\title{
DE FORA, DE CIMA E DE BAIXO - TODOS OS SENTIDOS DA DIGNIDADE NO DISCURSO DOS DIREITOS.
}

\author{
FROM OUT, ABOVE AND UNDER - ALL MEANINGS FROM DIGNITY IN THE \\ RIGHTS DISCOURSE
}

\author{
Melina Girardi Fachin ${ }^{1}$ \\ Marcos Alberto Rocha Gonçalves ${ }^{2}$
}

\section{RESUMO}

À luz do atual estado da arte é possível e/ou desejável ainda sustentar a partição das categorias teóricas dos direitos humanos, direitos fundamentais e direitos da personalidade? $\mathrm{O}$ atual desenvolvimento do fenômeno jurídico pátrio no âmbito internacional, constitucional e infraconstitucional motiva a presente indagação a medida em que os diversos enfoques que o fenômeno da globalização impôs e impõem, leva necessariamente a uma nova abordagem do direito marcado pelos movimentos em constante dialética. Assim sendo, explorando os diversos campos de diálogos que se abrem entre direitos será explorado a partir da revisão da bibliografia posta.

Palavras-chave: Direitos humanos - direitos fundamentais - direitos da personalidade constitucionalização - dignidade

\begin{abstract}
In light of the current discussion is it possible and/or desirable to further support the partition of theoretical categories of human rights, fundamental rights and personal rights? The current development of the Brazilian legal phenomenon in international, constitutional and infraconstitutional framework motivates this question especially of the different approaches that the phenomenon of globalization imposed and impose to a new approach to the rights discourse marked by movements in constant dialectic. Therefore, exploring the various dialogues fields that open between rights the theme will be explored from the review of the literature indicated.
\end{abstract}

Keywords: Human rights - fundamental rights - personality rights - constitutionalization dignity

\footnotetext{
${ }^{1}$ Doutora em Direito Constitucional e mestre em Filosofia do Direito Constitucional pela Pontifícia Universidade Católica - PUC, São Paulo, (Brasil). Visiting Researcher da Harvard Law. Professora da Faculdade de Direito da Universidade Federal do Paraná - UFPR, Curitiba. E-mail: melinafachin@gmail.com

${ }^{2}$ Doutorando em Direito Civil pela Universidade do Estado do Rio de Janeiro - UERJ. Mestre em Direito Civil pela Pontifícia Universidade Católica - PUC, São Paulo. Professor de Direito Civil da PUC-PR. Email: marcosargoncalves@gmail.com
} 


\section{NOTAS INTRODUTÓRIAS.}

A proposta desse ensaio que ora se coloca à reflexão é justamente responder, de modo crítico e construtivo, a pergunta que motivou a sua reflexão, qual seja: à luz do atual estado da arte é possível e/ou desejável ainda sustentar a partição das categorias teóricas dos direitos humanos, direitos fundamentais e direitos da personalidade?

O atual desenvolvimento do fenômeno jurídico pátrio no âmbito internacional, constitucional e infraconstitucional que motiva a presente indagação. Hoje não faz mais sentido entrever o direito ainda no marco clássico do dualismo ou monismo de fontes. Os diversos sentidos que o fenômeno da globalização impôs e impõe, leva necessariamente a uma nova abordagem do direito como um fenômeno impuro marcado pelos movimentos internos e internacionais em constante dialética.

Isso fica ainda mais exacerbado na área dos direitos. No âmbito internacional, o giro que se se coloca com a centralidade da pessoa humana, pós 1948, e o surgimento do direito internacional dos direitos humanos levaram a crescente positivação internacional e o trabalho ativo das cortes nesta matéria, para além dos empréstimos constitucionais do diálogo horizontal de jurisdições, tem dado um novo colorido ao tema.

No âmbito constitucional, ao menos ocidental, o Pós-Guerra também gerou seus impactos. Nesse sentido nota-se a emergência de um discurso constitucional renovado, permeado por valores e princípios - como a dignidade humana - figurando como componentes basilares dos sistemas. Destaque-se, a título de exemplo, a Lei Fundamental Alemã de 1949, em seu artigo $1^{\circ}$, ao tratar da dignidade da pessoa humana e dos direitos humanos. ${ }^{3}$

No âmbito constitucional brasileiro, esse movimento tardou, pois, apenas com o recompromisso democrático da Constituiçao Republicana de 1988 que foi possível a exibição desse paradigma constitucional. A partir daí os efeitos da constitucionalização se alçaram a todo ordenamento jurídico inferior dando abertura ao importante giro coperniquiano enunciado, urgindo que a regra infraconstitucional seja interpretada à luz dos princípios e ordenamentos constitucionais.

\footnotetext{
${ }^{3}$ Eis o texto da constituição alemã em tradução livre: "(1) A dignidade da pessoa humana é intangível. Respeitá-la e protegê-la é obrigação de todo o poder público. (2) O povo alemão reconhece, por isto, os direitos invioláveis e inalienáveis da pessoa humana como fundamento de toda comunidade humana, da paz e da justiça no mundo. (3) Os direitos fundamentais, discriminados a seguir, constituem direitos diretamente aplicáveis e vinculam os poderes legislativo, executivo e judiciário."
} 
Trata-se de uma nova concepção que coloca no centro das relações jurídicas o sujeito constituído a partir de sua dignidade, confrontando com um modelo de direito civil tradicional. Os desígnios constitucionais irradiam-se, como fundamento de validade, para todo o ordenamento jurídico a partir deste novo paradigma imposto pela Constituição, dá substrato ao chamado "direito civil constitucional", expressão pioneira no Brasil descortinada na obra de Gustavo Tepedino (TEPEDINO, 2008). Trata-se do reconhecimento do programa constitucional como norma fundante da construção jurídica das relações privadas.

Contempla esta ordem de ideias o magistério de Luiz Edson Fachin, para quem passa a dignidade da pessoa humana a figurar como centro do ordenamento constitucional e infraconstitucional:

\begin{abstract}
A dignidade da pessoa é princípio fundamental da Republica federativa do Brasil. É o que chama de princípio estruturante, constitutivo e indicativo das idéias diretivas básicas de toda ordem constitucional. (...) Aplica-se como leme a todo o ordenamento jurídico nacional compondo-lhe o sentido e fulminando de inconstitucionalidade todo preceito que com ele conflitar. É de um princípio emancipatório que se trata. (FACHIN, 2001. p. 180)
\end{abstract}

No âmbito infraconstitucional do domínio dos direitos da personalidade, o olhar dispensado pela doutrina às situações jurídicas contemporâneas possui a imperiosa deflexão própria do reconhecimento da unidade do sistema jurídica com vértice no conteúdo constitucional. Esse trilhar da construção discursiva do direito privado revela a centralidade da pessoa humana acima enunciada, projetando a tutela das situações jurídicas à prevalência da concretização da existência digna.

Nesse sentido, inegável a necessidade de tutelar os direitos da personalidade a partir de aplicação sistêmica das normas jurídicas, mesmo aquelas estruturalmente concebidas para o regramento das situações jurídicas patrimoniais. Não há, portanto, concorrência, mas sim reconhecimento da importância da temática irradiadora da dignidade humana com essa dúplice proteção, a saber:

Como categoria fundamental de direitos, os direitos da personalidade foram alvo de pontual proteção tanto pelo constituinte como pelo legislador infraconstitucional. Esta tendência a uma dupla proteção de institutos tipicamente democráticos, constitucional e infraconstitucional, insere-se no contexto do fenômeno denominado "constitucionalização do direito", marcado pela sintonia de todo Ordenamento Jurídico com seu elemento central, que é a Constituição, em torno da qual deve gravitar todo esse Ordenamento, conformando um sistema uno. (TAVARES, 2014. p. 889) 
Colhidos, portanto, todos os frutos desses diferentes campos é que a reflexão aqui se anima para - explorando pontos de convergência e divergência - ao final contribuir criticamente ao explicitado.

\section{DIREITOS HUMANOS - O OLHAR QUE VEM DE FORA.}

Foram os atos de terrorismo de Estado geradores das truculências do segundo grande conflito mundial que chamaram a consciência da possibilidade humana de destruir e aniquilar ao próximo e a si mesma. É da negativa de proteção jurídica aos direitos dos seres humanos espelhada na nefasta dissociação entre pessoa e sujeito de direitos que tem como base a óptica totalitarista da superfluidade e dispensabilidade de alguns indivíduos - que exsurge a reconstrução e reestruturação dos direitos humanos, sob o pálio da Declaração Universal de 1948.

Abriu-se, assim, um novo paradigma de proteção dos seres humanos que abandona seu viés unicamente doméstico (no qual se identificam com os direitos do cidadão ${ }^{4}$ ) e ganham proporções no cenário internacional. Isto porque suas consequências, no mais das vezes, como demonstrou a experiência da Guerra, não ficam adstritas aos limites fictos da geografia mundial. É este processo de câmbio dos direitos do cidadão em direitos humanos que marca a passagem da "era das catástrofes" 5 à "era dos direitos" (BOBBIO, 2004).

Acerca dessa travessia dos direitos do cidadão aos direitos humanos, cumpre frisar: "No final desse processo, os direitos do cidadão terão se transformado, realmente, positivamente, em direitos do homem. Ou, pelo menos, serão os direitos do cidadão daquela cidade que não tem fronteiras, porque compreende toda humanidade; ou, em outras palavras, serão os direitos do homem enquanto direitos do cidadão do mundo." (BOBBIO, 2004. p. 50)

O embrião da internacionalização, contido na concepção contemporânea dos direitos humanos, arrima-se, consoante desfiado, em dois alicerces bem demarcados, quais sejam: a

\footnotetext{
${ }^{4}$ Essa óptica da passagem dos cidadãos aos direitos humanos é registrada por Hannah Arendt na obra sobre As Origens do Totalitarismo, cuja passagem ora se reproduz: "Com o surgimento das minorias na Europa ocidental e meridional e com a incursão dos povos sem Estado na Europa central e ocidental, um elemento de desintegração completamente novo foi introduzido na Europa do após-guerra. A capacidade constitucional dos Estados-nações europeus de proteger os direitos humanos dos que haviam perdido os seus direitos nacionais permitiu aos governos opressores impor sua escala de valores até mesmo sobre países oponentes. Aqueles a quem haviam escolhido como refugo da terra - judeus, trotskistas etc. - eram realmente recebidos como refugo da terra em toda parte; aqueles quem a perseguição havia chamado de indesejáveis tornaram-se de fato os indésirables da Europa." (ARENDT, 1989. p.302).

${ }^{5}$ Expressão utilizada por Eric Hobsbawn para identificar a primeira "era", marcada, sobretudo, pelas guerras, que compõe o século XX. (HOBSBAWN, 1995).
} 
limitação da soberania estatal e de seu espaço autônomo em relação à proteção da pessoa humana, e uma visão universal e holística desses direitos.

A teoria tradicional da soberania dos Estados é revisitada à luz dos compromissos que os próprios entes estatais assumem, voluntariamente perante a comunidade internacional. Há, em consequência, revisão do princípio da soberania uma vez que os próprios Estados passam a admitir a assunção de limitações externas a partir de compromissos por eles assumidos espontaneamente. Do ponto de vista interno, a crise da soberania reflete a crise do próprio Estado. Nessa seara, deriva da ausência de um poder incontrastável - para utilizar a expressão de Jean Bodin - em relação aos demais poderes sociais. ${ }^{6}$

Destarte, o conceito clássico de soberania, compreendido como capacidade de uma ordem estatal autovincular-se e autodeterminar-se juridicamente de modo exclusivo (JELLINEK, 2000. p. 495), certamente carrega - a partir deste marco normativo internacional nó em seu âmago que até os dias correntes ainda não desatou.

Impende, por conseguinte, mirá-lo à luz de suas dimensões históricas e relativas porque, em que pese fruto do pensamento estatal moderno, nos dias atuais representa um atributo do poder político que se exerce de variados modos. No cenário contemporâneo, tornamse incompatíveis com arquitetura protetiva as ideias tradicionais da soberania do Estado Moderno. Corroboram a este aspecto, no âmbito externo, o processo de transnacionalização e a proliferação de ordenamentos soberanos transnacionais, e no âmbito interno, a emergência e consolidação de novos grupos sociais que também põem em xeque esta noção (CAMPILONGO, 1997. p. 1000).

Ao lado desta (re)visão da teoria da soberania, também introduz a Declaração compreensão universal e holística dos direitos humanos, que tem como premissa o reencontro das noções de pessoa, ser humano e sujeito de direitos, e como ideário a realização substancial de sua dignidade.

Repousa na Declaração Universal de 1948 o início de um projeto internacional protetivo e promocional que polvilhou suas sementes em diversos outros instrumentos normativos que

\footnotetext{
6 "A crise contemporânea desse conceito envolve aspectos fundamentais: de uma parte, a dificuldade de conciliar a noção de soberania do Estado com a ordem internacional, de modo que a ênfase na soberania do Estado implica sacrifício maior ou menor do ordenamento internacional, e vice-versa, a ênfase neste se faz com restrições de grau variável aos limites da soberania, há algum tempo tomada ainda em termos absolutos; doutra parte, a crise se manifesta sob aspecto e a evidência de correntes doutrinárias ou fatos que ameaçadoramente patenteiam a existência de grupos e instituições sociais concorrentes, as quais disputam ao Estado sua qualificação de ordenamento político supremo, enfraquecendo e desvalorizando por consequência a ideia mesma de Estado". (BONAVIDES, 2011. p.133).
} 
colonizaram a paisagem dos direitos humanos que não se restrigem ao âmbito exclusivamente internacional. Sobre o fato de a Declaração de 1948 conter o gérmen da internacionalização indica Bobbio:

\begin{abstract}
Quando se diz que a Declaração Universal representou apenas o momento inicial da fase final de um processo, o da conversão universal em direitos positivos do homem, pensa-se habitualmente na dificuldade de implementar medidas eficientes para a sua garantia numa comunidade como a internacional, na qual ainda não ocorreu o processo de monopolização da força que caracterizou o nascimento do Estado moderno. Mas também há problemas de desenvolvimento, que dizem respeito ao próprio conteúdo da Declaração. Com relação ao conteúdo, ou seja, à quantidade e à qualidade dos direitos elencados, a Declaração não pode apresentar nenhuma pretensão de ser definitiva. (BOBBIO, 2004. p. 51)
\end{abstract}

Isto porque está cada vez mais difícil de divisar as fronteiras dessas duas searas. O jardim e a praça, nos dizeres de Nelson Saldanha (SALDANHA, 2003) são nascidos dos mesmos princípios e voltados ao mesmo fim constitucionalmente estabelecido que é a tutela concreta dos sujeitos.

Nessa perspectiva jurídica, é fundamental remarcar que as pessoas é que são as destinatárias do direito, desta catarse é que desaponta a proteção da pessoa humana. Surge assim, como destaca Eduardo Novoa Monreal, "a imagem do homem coletivo, pertencente a uma coletividade viva e integrada, conforme uma ordem socialmente orientada, na qual se tende a nivelar os indivíduos em um plano que permita, nas melhores condições possíveis, o maior desenvolvimento de todos eles" (MONREAL, 1979. p. 155).

Convergem, portanto, âmbitos externos e internos em prol da maior e melhor proteção dos indivíduos.

\title{
3. DIREITOS FUNDAMENTAIS - O OLHAR QUE VEM DE CIMA.
}

O pós-guerra representa no marco dos ordenamentos constitucionais, colhendo todos os frutos da paisagem internacional, o recompromisso com os direitos e sua centralidade normativa e valorativa. O princípio da dignidade humana aponta para o reencontro axiológico do direito já que o excesso de formalismo jurídico foi um dos alicerces de legalidade (em sentido estrito) que se tornou instrumento dos horrores do ocaso do direito.

É a Constituição vigente que permitiu o desabrochar da tutela da pessoa humana na ordem jurídica pátria contemporânea. A redemocratização reclamou a (re)construção e o fortalecimento da democracia para a superação do legado autoritário e a construção das possibilidades de futuro. Os direitos da pessoa humana auxiliam nessa trajetória democrática visto que são, ao 
mesmo tempo, consequência e instrumento da realização do direito à participação políticodemocrática necessária e reclamada pela justiça transicional. É instrumental na medida em que assegura a participação política dos indivíduos nos destinos da comunidade política à qual pertence. É, em outra medida, consequente, porque a participação democrática demanda patamar mínimo de garantias materiais, econômicas e sociais para que possam ser sujeitos ativos formuladores de suas demandas.

Possibilitou-se, assim, um avanço significativo no reconhecimento e na tutela dos direitos fundamentais, conectando-os com as obrigações internacionais. Isto porque as alterações constitucionais produziram importantes efeitos externos com "o equacionamento dos direitos humanos no âmbito da ordem jurídica interna serviu como medida de reforço para que a questão dos direitos humanos se impusesse como tema fundamental na agenda internacional do país" (PIOVESAN, 2012. p. 80).

Dessarte, a primazia e a centralidade da pessoa humana nesse redesenho constitucional abrem a possibilidade de estreitamento constitucional com o direito infraconstitucional. É em torno da proteção da dignidade humana que essas esferas gravitam.

O princípio da dignidade da pessoa humana possui vida recente na história constitucional brasileira uma vez que foi o texto constitucional presente o primeiro a abraçar, em positivação expressa, o referido princípio. Ao assim fazê-lo, já em seu primeiro artigo (art. 1. ${ }^{\circ}$, III), conferiu ao referido princípio função basal de toda a ordem estatal. A recepção no texto constitucional espelhou o caminhar encetado pelo direito internacional dos direitos humanos e por outros ordenamentos constitucionais ocidentais ${ }^{7}$ que assim o fizeram previamente.

Recolheu, pois, a diretriz que pavimentou o caminho após o fim da Segunda Grande Guerra, na qual a concepção contemporânea da intangibilidade da dignidade da pessoa humana veio a consolidar-se e irradiar-se por todo o ordenamento.

Conforme sintetizou Ricardo Aronne, "deve-se ter presente que toda a interpretação jurídica é interpretação sistemática, de modo que toda a exegese há de ser uma interpretação conforme a Constituição. A Constituição Federal é a matriz axiológica de todo o ordenamento jurídico" (ARONNE, 2003. p. 240).

\footnotetext{
${ }^{7}$ Não apenas ordenamentos constitucionais ocidentais aderiram ao princípio: "Isso inclui, entre outras, as constituições da Alemanha, Itália, Japão, Portugal, Espanha, África do Sul, Brasil, Israel, Hungria e Suécia. Alguns países, como Irlanda, Índia e Canadá, fazem referência à dignidade humana no preâmbulo das suas constituições". Independente de sua previsão constitucional, "há um razoável consenso de que ela constitui um valor fundamental subjacente às democracias constitucionais de modo geral, mesmo quando não expressamente prevista nas suas constituições". (BARROSO, 2012).
} 
Entrever e pensar o direito civil a partir da ótica social do constituinte de 1988 não se trata de mera alteração metodológica, tal percepção, fundada nos elementos principiológicos trazidos pela Constituição de 1988, importa, sobretudo, na noção primaz da proteção material da dignidade da pessoa humana.

Pontua sobre o tema Wilson Steinmetz:

Seja como norma-princípio constitucional fundamental autônoma, seja como conteúdo que se expressa ou se concretiza nos direitos fundamentais, a dignidade da pessoa vincula os poderes públicos. Mas não exclusivamente eles. Vincula também os particulares à medida que a CF normaliza âmbitos de vida nos quais o Estado não participa ou não participa diretamente e à medida que os particulares - de modo especial, quando detentores de poder econômico, social e ideológico - são potenciais violadores da dignidade da pessoa. Dado o fato de que a dignidade da pessoa é fundamento da República Federativa do Brasil, é inaceitável, por falta absoluta de consistência normativa e justificação racional, teórica e dogmática, a não vinculação dos particulares à dignidade da pessoa como princípio objetivo autônomo e a não vinculação a direitos fundamentais, direitos que, repita-se, são a expressão, em nível menos abstrato, da dignidade da pessoa. (STEINMETZ, 2003. p. 83)

É sob esta mirada que se busca enfrentar o discurso jurídico dos direitos da personalidade ressignificado. Consoante aponta Perlingeri:

\begin{abstract}
No personalismo confluem as ideologias que, depois da Segunda Guerra Mundial, encontraram um compromisso político nos princípios fundamentais das novas democracias ocidentais e, em parte, daquelas orientais (...). Livre de referências polêmicas e confortado pela evolução paralela do pensamento liberal, desde o interesse individual egoísta (maximização da prosperidade) ao reconhecimento da irredutível pluralidade de valores humanos, o personalismo não mais pertence a uma específica corrente de pensamento. A 'pessoa' - entendida como conexão existencial em cada indivíduo de estima em si, do cuidado com o outro e da aspiração de viver em instituições justas - é hoje o ponto de confluência de uma pluralidade de culturas, que nela reconhecem a sua própria referência de valores. (...) O princípio da tutela da pessoa, como supremo princípio constitucional, funda a legitimidade do ordenamento e a soberania do Estado. (PERLINGIERI, 2008. p. 459-461)
\end{abstract}

\title{
4. DIREITOS DA PERSONALIDADE - O OLHAR QUE VEM DE BAIXO.
}

Como explicita Anderson Schreiber, a expressão direitos da personalidade surgiu no curso dos acontecimentos da segunda metade do século XIX, período histórico marcado por contundentes tensões sociais e econômicas. Foi nesse contexto histórico da segunda metade do século XIX, marcado por injustiças e revoltas, que surgiram as primeiras construções em torno dos direitos da personalidade. 
A expressão foi concebida por jusnaturalistas franceses e alemães para designar certos direitos inerentes ao homem, tidos como preexistentes ao seu reconhecimento por parte do Estado. Eram, já então, direitos considerados essenciais à condição humana, direitos sem os quais 'todos os outros direitos subjetivos perderiam qualquer interesse para o indivíduo, ao ponto de se chegar a dizer que se não existissem, a pessoa não seria mais pessoa" (SCHREIBER, 2013. p. 5).

Tratou-se, com a expressão, da enunciação de direitos tidos como fundamentais à própria condição humana, moldura essa que, ressignificada pelas transformações contemporâneas, ainda guarda em seu material genético a essência funcional de conversão de todo o sistema à proteção jurídica da pessoa e sua dignidade.

A propósito da amplificação do sentido funcional dos direitos da personalidade, Schreiber leciona que se trata de mecanismo que visa "proteger a condição humana, em seus mais genuínos aspectos e manifestações, tomando a pessoa 'sempre como um fim e nunca como um meio'. Nesse sentido é que se revela 'contrario à dignidade humana, tudo aquilo que puder reduzir a pessoa (o sujeito de direitos) à condição de objeto" (SCHREIBER, 2013. p. 8).

É a partir dessa concepção que se expressam, imediatamente, de um lado o conteúdo estabelecido pelo artigo $5^{\circ}$ da Constituição da República de 1988, que enuncia o rol aberto dos direitos fundamentais e, de outro, no prisma restrito das relações jurídicas privadas, nos artigos 11 a 21 do Código Civil de 2002. Especificamente no que toca à norma infraconstitucional, elegeu o legislador como centros de interesse protegidos o corpo, o nome, a honra e imagem e a privacidade.

A presença de tal conteúdo normativa, especialmente por sua localização arquitetônica na Parte Geral do Código demonstra a "afirmação do compromisso de todo o direito civil com a tutela e a promoção da personalidade humana" (SCHREIBER, 2013. p. 8), em reforço a ideia de que todo o sistema normativo deve prestar contas à tutela da dignidade da pessoa.

Assim, ao lado de toda a crítica pertinente à formatação da codificação civil vigente, especialmente relativa a incongruência de seu modelo estruturante com a compreensão contemporânea marcadamente aberta ao arejamento funcional das normas, importa reconhecer que em determinados aspectos o Código Civil de 2002 refletiu o que anos antes Orlando Gomes designou de revolução na cultura jurídica ${ }^{8}$, impondo a sobreposição dos valores relacionados à dignidade nas múltiplas relações jurídicas reguladas pelo diploma.

\footnotetext{
8 “A revolução na cultura jurídica não atinge apenas os pressupostos culturais do Direito Privado. Implica, também, sua renovação em vista da necessidade de enfocar as relações sociais desde outro ângulo, tão certo é, como atesta
} 
Nesse cenário, considerando de um lado a força expansiva da constituição na tutela desses direitos e sua clara associação com o programa constitucional, de um lado, e, de outro, os limites postos por um modelo de direito civil codificado comprometido com o olhar do passado, é que ganha sentido e relevância questionar-se acerca da mantença dessa divisão entre direitos humanos, fundamentais e da personalidade.

Toda a estrutura positiva do regramento privado infraconstitucional segue a racionalidade patrimonial moderna, desde a regulação da pessoa, da propriedade e das relações

familiares. É preciso compreender, porém, que o instrumental jurídico que respalda essa configuração social nos moldes do discurso da modernidade passa a ganhar diferentes contornos com o surgimento de uma "nova" perspectiva social, econômica, política e jurídica, assentada na doutrina do Estado Social. No Brasil, esta perspectiva encontra-se alicerçada simbolicamente na Constituição de 1988, mais especificamente com abertura do texto constitucional expressa ou implicitamente a vários axiomas relevantes.

A centralidade da tutela dos direitos da personalidade impõe ao intérprete esforço construtivo da norma, ampliando a função dos conteúdos teóricos enraizados na codificação em adequação ao sentido protetivo revelado pelo momento pós-constitucional, sendo um dos conteúdos potencialmente relevante nessa missão a cláusula geral da boa-fé objetiva.

Abre-se, igualmente, um espaço para aplicação dos direitos fundamentais nas relações interprivadas através das cláusulas gerais ou, na acepção de Karl Larenz, pautas de valoração que carecem de preenchimento valorativo: ordem pública, boa-fé, abuso de direito, função social, etc. (LARENZ, 2003. p. 311). Aliás, o Código Civil de 2002, em seu artigo 2.035, parágrafo único, dispõe expressamente que: “nenhuma convenção prevalecerá se contrariar preceitos de ordem pública, tais como os estabelecidos por este Código para assegurar a função social da propriedade e dos contratos".

Colhe-se, a este respeito, a observação de Gustavo Tepedino:

O novo Código nascera velho principalmente por não levar em conta a história constitucional brasileira e a corajosa experiência jurisprudencial, que protegem a personalidade humana mais do que a propriedade, o ser mais do que o ter, os valores existenciais mais do que os patrimoniais. E é demagógico porque, engenheiro de obras

a experiência jurídica dos tempos presentes, que alguns princípios, construções e conceitos formulados, com rigor lógico, pela ciência pandectista, como suma expressão do positivismo científico, carecem de revisão ante a impossibilidade de se lhes ajustar novas formas de comportamento. É evidente que passando o modo de agir na sociedade a se condicionar a interesses coletivos, vigilantemente defendidos pelo Estado e por grupos de potencialidade social desenganada, a quantidade das ações orientadas nesse sentido converte-se necessariamente em qualidade, isto é, determina novo tratamento, a que se tornaram imprestáveis princípios, construções e conceitos ordenados em função de outro tipo de conduta”. (GOMES, 1980. p. 05). 
feitas, pretende consagrar direito que, na verdade, estão tutelados em nossa cultura jurídica pelo menos desde o pacto político de outubro de 1988. (TEPEDINO, 2008. p. 359)

Conforme pontua Teresa Negreiros, a boa-fé objetiva acomoda o valor da ética, formatada a partir da observância de comportamento leal, com irradiação difundida em todo o fenômeno contratual e, acrescentamos, em todas as implicações das relações jurídicas contratualizadas - marca indelével do atual momento social - na esfera dos direitos da personalidade. Isso se dá porque trata-se de princípio com fundamento constitucional, assentado, como revela a autora, no mandamento central de tutela da pessoa humana, adicionando: "Mais especificamente, é possível reconduzir o princípio da boa-fé ao ditame constitucional que determina como objetivo fundamental da República a construção de uma sociedade solidária, na qual o respeito pelo próximo seja um elemento essencial de toda e qualquer relação jurídica” (NEGREIROS, 2002. p. 116-117).

Trata-se de verdadeiro giro hermenêutico, autorizado em fundamento constitucional e com sentido teleológico consentâneo com a centralidade da dignidade humana. Embora bastante atraente, referida ordem de ideias recomenda, porém, a necessária cautela em sua execução.

Um primeiro aspecto que ressaí é da ordem do rigor técnico, não se podem torcer categorias teóricas a fim de se operacionalizar resultados que, em um determinado momento, apareçam como mais atraentes. Os modelos hermenêuticos têm que ser universalizáveis e se sustentar independentes da postura consequencialista que se busca.

Um segundo aspecto enfoca nos sujeitos ativos deste processo interpretativo, o Poder Judiciário. Conferir um excesso de protagonismo ao Poder Judiciário, aniquilando espaços importantes do conteúdo da autonomia privada, não atende aos anseios da própria proteção dos direitos. Assim sendo, não se pode basear o modelo de compatibilização das previsões do código (direitos da personalidade) com aquelas da Constituição (direitos humanos e fundamentais) tão-somente na conduta do Estado-juiz.

$\mathrm{O}$ acima exposta mostra que diversas pontas surgem da tentativa de harmonização e compatibilização da manutenção de um discurso partido de direitos, pautados por matrizes diversas entre o Código e a Constituição.

\section{NEM ACIMA, NEM ABAIXO, NEM AO LADO - JUNTOS!}


Nada obstante esse norte dicotômico ter prevalecido, desnudou-se a dificuldade desta abordagem partida que, por questões ideológicas, levaram à discrepância na tratativa dos direitos; a partir dessa predisposição de ambivalência; formaram-se, consoante acima demonstrado, argumentos que se espraiam - sobretudo pelos campos econômico, político e jurídico - que, todavia, não se sustentam.

Não há como negar que esse divórcio possui conexões e também consequências políticas; Política é aqui entendida no sentido arendtiano, cuja finalidade e razão de ser são marcadas pela liberdade humana e baseada, de um lado, na pluralidade dos homens, e, de outro, na convivência entre diferentes. Nas palavras da autora: "Política, assim aprendemos, é algo como uma necessidade imperiosa para a vida humana, na verdade, tanto para a vida do indivíduo como da sociedade. Como o homem não é autárquico, porém depende de outros em sua existência, precisa haver um provimento de vida relativo a todos, sem o qual não seria possível justamente o convívio. Tarefa e objetivo da política é a garantia de vida no sentido mais amplo." (ARENDT, 2004. p. 45-46).

Obviamente que os direitos são categoria diversa e complexa que, por vezes, necessitam de arquétipos diferenciados para sua realização. Todavia, sua plena realização apenas será alcançada se abraçada a heterogeneidade que reside no seu âmbito. A diferenciação deve ser razão da promoção de direitos, tomados em sua relação integral de complementaridade, e não de divisão, subjugação e hierarquização de determinadas categorias em face de outras.

A dignidade humana apresenta-se como conteúdo comum (VIEIRA DE ANDRADE, 1987. p. 83) a todos os direitos fundamentais e, tendo em vista o estampado no art. $1^{\circ}$, III da Constituição de 1988, é fundamento do Estado Constitucional que deve ser consolidado pela concretização dos direitos fundamentais. São os espaços ativos e passivos da dignidade da pessoa humana que se abrem. Ronald Dworkin refere-se ao sentido agente e paciente da dignidade da pessoa humana, pois, esta possui "tanto uma voz ativa quanto uma voz passiva e que ambas encontram-se conectadas" (DOWRKIN, 2003. p. 306).

Ressaltando, portanto, o campo de obrigações, em especial as ditas positivas, que o princípio da dignidade da pessoa humana impõe à atuação estatal afirma Perez Luño que "a dignidade da pessoa humana constitui não apenas a garantia negativa de que a pessoa não será objeto de ofensas ou humilhações, mas implica também, num sentido positivo, o pleno desenvolvimento da personalidade de cada indivíduo" (LUÑO, 2003. p. 318)

Complementares a este pensamento são as ideias expressadas por Paulo da Mota Pinto para quem "a garantia da dignidade da pessoa humana decorre, desde logo, como verdadeiro 
imperativo axiológico de toda a ordem jurídica, o reconhecimento de personalidade jurídica a todos os seres humanos, acompanhado da previsão de instrumentos jurídicos (nomeadamente, direitos subjetivos) destinados à defesa das refrações essenciais da personalidade humana, bem como a necessidade de proteção desses direitos por parte do Estado". (MOTA PINTO, 1999. p. 151-152).

Em que pese não se poder identificar um conceito fechado determinante dos direitos, pode-se inferir que todos os direitos em sua materialidade convergem à ideia de realização da dignidade da pessoa humana. Esse significado é sublinhado por Paulo da Mota Pinto, para que a garantia da dignidade da pessoa humana traduz, de um lado, a "afirmação da liberdade de desenvolvimento da personalidade humana" e, de outro, "o imperativo de promoção das condições possibilitado rãs desse livre desenvolvimento constituem já corolários do reconhecimento da dignidade da pessoa humana como valor no qual se baseia o Estado" (MOTA PINTO, 1999. p. 152).

A força expansiva dos direitos e da dignidade projeta a Constituição para outros rincões, alargando seu ambito de proteçao. É nesse sentido de alargamento que se pronuncia Gomes Canotilho: "o parâmetro constitucional é mais vasto do que as normas e princípios constantes das leis constitucionais escritas, devendo alargar-se, pelo menos, aos princípios reclamados pelo espírito ou pelos valores que informam a ordem constitucional global" (CANOTILHO, 2002 p. 811).De fato, conforme aponta Konrad Hesse, em conhecida lição, “a constituição não é mais apenas a ordem jurídico-fundamental do Estado, tornando-se a ordem jurídico-fundamental da sociedade" (HESSE, 1992. p. 16).

Nessa esteira de ampliação do catálogo emerge o parágrafo $2 .^{\circ}$ do artigo $5 .^{\circ}$ da Carta Constitucional pátria, na perspectiva de abertura do rol material dos direitos fundamentais para incluir, dentre outros, aqueles advindos dos tratados internacionais ratificados pelo Brasil. Ao consignar que os direitos expressos na Constituição não excluem outros decorrentes do regime e dos princípios por ela adotados, ou dos tratados internacionais em que o Brasil seja parte, o constituinte originário abriu as portas do texto constitucional ao direito internacional dos direitos humanos.

Assim sendo, não é uma faculdade, mas sim, um imperativo constitucional tratar dos direitos como um todo holístico e integral em torno dos valores de dignidade que gravitam.

O reconhecimento da unidade do ordenamento a partir da centralidade da Constituição conduz a construção normativa de todo o arcabouço do sistema jurídico em observância à concretização da pessoa humana e sua existência digna. Implica afirmar que todas as situações 
jurídicas, ainda que não diretamente constituídas para a concretização dos direitos fundamentais, têm o dever funcional de resguardá-los. Nesse cenário, mesmo os princípios pertinentes às situações jurídicas patrimoniais, como a boa-fé objetiva, se funcionalizam à tutela da dignidade da pessoa humana.

\section{CONCLUSÃO.}

Direitos humanos, direitos fundamentais e direitos da personalidade - todos convergem para o mesmo fim e sentido de prevenir o sofrimento humano e resguardar sua dignidade (FLORES, 2009. p. 32). A afirmação histórica dos direitos da pessoa humana, leciona Fábio Konder Comparato, fora aprofundada pela dor e sofrimento, ambas, a um só tempo, destruidoras deum dado modo de ser e estar e construtoras de uma nova compreensão de direitos (COMPARATO, 2001.p. 444)

Tradicionalmente direitos humanos são terminologia predileta da arena internacional, direitos fundamentais do âmbito constitucional e direitos da personalidade da seara privada do direito civil. Esta abordagem estanque não combina, todavia, com os influxos multinivelados que influenciam o fenômeno jurídico contemporâneo.

"O crescente reconhecimento da interdependência das sociedades, devido a contatos transnacionais, leva à necessidade de uma aproximação global dos problemas" (PERRONEMOISES, 1999. p. 191). Surge, assim, a solidariedade como um valor chave dessa nova arquitetura como o anverso da moeda dos diálogos e da cooperação entre os sistemas de ângulo interno e internacional.

Resta claro, portanto, que se esta a tratar de categorias inequivocamente próximas afastadas por um tratamento legislativo codificado ainda inspirada em valores de antanho sendo que seus sentidos podem - e devem - se somar em busca da efetiva proteção da pessoa humana no caso concreto. Sublinha Bilbao Ubillos que "el princípio de la dignidad humana tiende a superar el tradicional aislamiento de la Constituicíon del resto del ordenamiento, tiene uma gran transcendência en la medida em que impide que el Derecho Constitucional y el Derecho privado puedan concebirse como compatimientos estancos, como mundos separados,

que discurren em paralelo y están gobernados por logicas radicalmente"(BILBAO UBILLOS, 2003. p. 304).

Justamente por esta razão, reconhecendo e afirmando as particularidades ainda existentes, faz-se necessário o tratamento associado das categorias dos direitos humanos, dos 
direitos fundamentais e dos direitos da personalidade. Prosseguir tratando os temas de modo dissociado, permitindo que cada qual seja submetido a uma lógica monista insular - de direito internacional apenas, de direito interno apenas, de direito privado apenas, por exemplo - não da conta da realidade complexa da vida das vítimas que se quer proteger.

As categorias jurídicas em questão não são maiores que os sujeitos por eles designados. O esgrimir conceitos, ainda que seja teoricamente relevante, não pode nem deve obstar a realização dos fins a que os mecanismos protetivos se predispõem.

O legado da Declaração Universal de Direitos Humanos ainda, concretamente, não se realizou, sendo a concepção de integralidade, interdependência, indivisibilidade e universalidade do conteúdo dos direitos humanos promessa a cumprir, nos planos interno e internacional. A implementação desses direitos já encontra em sua prática habitual diversos óbices a serem superados de modo que a bipartição conceitual nos parece apenas mais uma barreira na via de implementação prática dos direitos.

\section{BIBLIOGRAFIA BÁSICA.}

ARENDT, Hannah. As origens do totalitarismo. São Paulo: Cia das Letras, 1989.

O que é política? 5.ed. Rio de Janeiro: Bertrand Brasil, 2004.

ARONNE, Ricardo. Titularidades e apropriação no novo Código Civil brasileiro - Breve ensaio sobre a posse e sua natureza. In: SARLET, Ingo Wolfgang. (Org.). O Novo Código Civil e a Constituição. Porto Alegre: Livraria do Advogado, 2003.

BARROSO, Luís Roberto. "Aqui, lá e em todo lugar": a dignidade humana no direito contemporâneo e no discurso transnacional. Separata da Revista dos Tribunais, São Paulo, v.101, n.919, p.135, maio 2012.

BILBAO UBILLOS, Juan Maria. ?En qué medida vinculan a los particulares los derechos fundamentales? In: SARLET, Ingo Wolfgang. Constituição, Direitos Fundamentais e Direito Privado. Porto Alegre: Livraria do Advogado, 2003.

BOBBIO, Norberto. A era dos direitos. Nova edição. Rio de Janeiro: Elsevier, 2004. 
BONAVIDES, Paulo. Ciência política. 18.ed. São Paulo: Malheiros, 2011.

CAMPILONGO, Celso Fernandes. Direito e democracia. São Paulo: Max Limonad, 1997.

CANOTILHO, José Joaquim Gomes. Direito constitucional e teoria da constituição. 6.ed. Coimbra: Almedina, 2002.

COMPARATO, Fábio Konder. Afirmação histórica dos direitos humanos. 2. ed. São Paulo: Saraiva, 2001.

DWORKIN, Ronald. O Domínio da Vida: aborto, eutanásia e liberdades individuais . São Paulo: Martins Fontes, 2003.

FACHIN, Luiz Edson. Estatuto jurídico do patrimônio mínimo. $2^{\mathrm{a}}$ ed. Rio de Janeiro: Renovar, 2006.

FLORES, Joaquín Herrera. A (re)invenção dos direitos humanos. Florianópolis: Boiteux, 2009.

GOMES, Orlando. Transformações Gerais do Direito das Obrigações. São Paulo: Editora Revista dos Tribunais, 1980.

HESSE, Konrad. Escritos de Derecho Constitucional. Madrid: Centro de Estúdios Políticos y Constitucionales, 1992.

HOBSBAWN, Eric. A era dos extremos: o breve século XIX (1914-1991). São Paulo: Companhia das Letras, 1995.

JELLINEK, Georg. Teoría General del Estado. México: FCE, 2000.

LARENZ, Karl. Metodologia da Ciência do Direito. $4^{\text {a }}$. ed. Trad: José Lamarego. Lisboa: Caloustre Gulbenkian, 2005.

MONREAL, Eduardo Novoa. El Derecho de Propiedad Privada. Bogotá: TEMIS, 1979. 
MOTA PINTO, Paulo. O direito ao livre desenvolvimento da personalidade. Coimbra: Coimbra Editora, 1999.

PERLINGIERI, Pietro. O Direito Civil na legalidade constitucional. Trad. Maria Cristina de Cicco. Rio de Janeiro: Renovar, 2008.

PERRONE-MOISÉS, Claudia. Direito humanos e desenvolvimento: a contribuição das Nações Unidas. In: AMARAL JR., Alberto do; PERRONE-MOISÉS, Claudia. O Cinqüientenário da Declaração Universal dos Direitos do Homem. São Paulo: Edusp/Fapesp, 1999.

NEGREIROS, Teresa. Teoria do Contrato: novos paradigmas. Rio de Janeiro: Renovar, 2002.

SALDANHA, Nelson. O Jardim e a Praça. São Paulo: Edusp, 2003.

SCHREIBER, Anderson. Direitos da Personalidade. 2a ed. São Paulo: Atlas, 2013.

STEINMETZ, Wilson. Vinculação dos particulares a direitos fundamentais. Eficácia jurídica. Curitiba. Tese (Doutorado em Direito). Setor de Ciências Jurídicas, Universidade Federal do Paraná, 2003.

TAVARES, André Ramos. Aspectos Constitucional-civis do Direito Fundamental à Imagem. In: LEAL, Pastora do Socorro Teixeira (coord.). Direito Civil Constitucional: e outros estudos em homenagem ao Prof. Zeno Veloso. São Paulo: Gen, 2014.

TEPEDINO, Gustavo. Temas de Direito Civil. Tomo II. Rio de Janeiro: Renovar, 2008.

VIEIRA DE ANDRADE, José Carlos. Os Direitos Fundamentais na Constituição Portuguesa de 1976. Coimbra: Almedina, 1987. 